

O ESPAÇO GEOGRÁFICO EM ANÁLISE

\title{
TÉCNICAS DE GEOPROCESSAMENTO APLICADAS NA IDENTIFICAÇÃO DE USOS DA TERRA NO ENTORNO DAS TURFEIRAS DA SERRA DO ESPINHAÇO MERIDIONAL
}

\section{GEOPROCESSING TECHNIQUES APPLIED ON IDENTIFICATION OF LAND USES IN THE SURROUNDINGS OF THE BOGS OF THE SERRA DO ESPINHAÇO MERIDIONAL}

\begin{abstract}
Samuel Ferreira da Fonseca ${ }^{1}$, Alexandre Christófaro Silva ${ }^{2}$, Juliano Alves de Senna ${ }^{3}$
RESUMO

Turfeiras são produtos da lenta decomposição de vegetais em ambientes saturados com água. Estes ecossistemas acumulam grandes volumes de matéria orgânica e preservam registros paleoclimáticos. O objetivo deste trabalho foi cartografar a evolução cronológica (1964 - 2014) da ocupação antrópica em de áreas adjacentes às turfeiras da Serra do Espinhaço Meridional para identificar impactos ambientais. Para o estudo foram utilizados dados de sensoriamento remoto, como fotografias aéreas e imagens dos satélites Landsat (TM/5 e OLI/8), analisados por técnicas de geoprocessamento. Os dados foram processados em várias etapas (e.g., georreferenciamento, mosaicagem, classificação supervisionada (MaxVer) e vetorização). A partir dos resultados foi possível identificar os tipos de uso da terra (pastagem, eucalipto e outras culturas) nas adjacências das turfeiras. Também foi constatado que a atividade agrícola mais intensa nas áreas estudadas foi o cultivo de eucalipto. Este cultivo era inexistente em 1964, e em 2014 ocupava 341,37 ha (2,07\% da área adjacente total). Outras culturas (milho, café e morango), não cultivadas na área desta pesquisa em 1964, passaram a ocupar 312,46 ha $(1,90 \%)$ em 2014 . As pastagens passaram de 378,57 ha em 1964 para 522,57ha em 2014, (um avanço de 2,30\% para 3,17\%) da área adjacente total.
\end{abstract}

Palavras-chave: Geoprocessamento, reservatório de água, turfeiras, ecossistema

\section{ABSTRACT}

Peat bogs are products of slow decomposition of plants in environments saturated with water. These ecosystems accumulate large volumes of organic matter and preserve paleoclimatic records. The objective of this work was to map the chronological evolution (1964 - 2014) of the anthropic occupation in areas adjacent to the bogs of the Serra do Espinhaço Meridional to identify environmental impacts. For the study, remote sensing data, such as aerial photographs and Landsat (TM/5 and OLI/8) satellites, were analyzed using geoprocessing techniques. Data were processed in several steps (e.g. georeferencing, mosaicking, supervised classification (MaxVer) and vectorization). From the results it was possible to identify the types of land use (pasture, eucalyptus and other crops) in the vicinity of peat bogs. It was also verified that the most intense agricultural activity in the studied areas was the cultivation of eucalyptus. This crop was non-existent in 1964, and in 2014 it occupied 341.37 ha $(2.07 \%$ of the total adjacent area). Other crops (corn, coffee and strawberry), which were not cultivated in this research area in 1964, began to occupy 312.46 ha $(1.90 \%$ ) in 2014. Pastures increased from 378.57 ha in 1964 to 522.57ha in 2014, (an advance from $2.30 \%$ to $3.17 \%$ ) of the total adjacent area.

Key-words: Geoprocessing, water reservoir, peat bogs, ecosystem

Recebido em: 10/04/2017

Aceito em: 15/02/2018

\footnotetext{
${ }^{1}$ Universidade Federal dos Vales do Jequitinhonha e Mucuri-, Diamantina/MG, e-mail: fonsekageo@gmail.com

2 Universidade Federal dos Vales do Jequitinhonha e Mucuri-, Diamantina/MG, e-mail:

alexandre.christo@ufvjm.edu.br

${ }_{3}$ Universidade Federal dos Vales do Jequitinhonha e Mucuri-, Diamantina/MG, e-mail: jsenna@ict.ufvjm.edu.br
} 


\section{TÉCNICAS DE GEOPROCESSAMENTO APLICADAS NA IDENTIFICAÇÃO DE USOS DA TERRA NO ENTORNO DAS TURFEIRAS DA SERRA DO ESPINHAÇO MERIDIONAL}

INTRODUÇÃO

Turfeiras são produtos da lenta decomposição de vegetais em ambientes saturados com água. São ecossistemas particulares (Gore, 1983) por acumularem grandes volumes de água e matéria orgânica e atuam como registros cronológicos de mudanças climáticas e ambientais nas escalas local, regional e global (Silva et al., 2009ab; Schellekens et al., 2014; Horak-Terra et al., 2014; Bispo et al., 2016; Campos et al., 2016). As turfeiras são sensíveis às alterações climáticas e vulneráveis a perturbações antrópicas decorrente de sua fragilidade. Estes ecossistemas dependem do regime hídrico local, das condições climáticas e ambientais específicas, tais como clima de montanha. Além disso, as turfeiras atuam no sequestro de carbono da atmosfera e armazenam grandes volumes de água (Squeo et al., 2006; Silva et al., 2009a; 2013a; Hórak-Terra et al., 2015; Silva e Silva, 2017; Campos et al., 2017).

A Serra do Espinhaço Meridional (SdEM) é o principal manancial de turfeiras de altitude do Brasil. Nesta região as turfeiras ocorrem preferencialmente em depressões, confinadas entre maciços quartzíticos, anteriormente preenchidas por rochas mais susceptíveis ao intemperismo (e.g., filitos, rochas metabásicas), devido à facilidade para o acúmulo do material orgânico (Campos et al., 2016). As turfeiras da SdEM armazenam aproximadamente 142.138.262 $\mathrm{m}^{3}$ de água, além de estocarem cerca de 2.693.196 toneladas de carbono, em uma área de 1.180.109 ha (Silva et al., 2013b; Silva e Silva, 2017).

O mapeamento de turfeiras é etapa básica para a estimativa da reserva de carbono e água nestes ecossistemas (Silva e Silva, 2017). Exemplos interessantes foram realizados em planícies do oeste da Sibéria (Rússia), que conseguiram inventariar turfeiras e registrar seu estoque de carbono, utilizando o sistema de informação geográfica (SIG) (Sheng et al. 2004). As técnicas do geoprocessamento foram bem sucedidas quando aplicadas na SdEM. Os principais estudos são os de Silva et al., (2013b) que conseguiram mapear 14.288 ha de turfeiras em 1.180.000 ha, e Campos et al., (2016) que analisaram as relações geomorfológicas, hidrológicas e evolutiva das turfeiras.

As técnicas do sensoriamento remoto (SR) também têm ajudado na caracterização destas entidades. Através de análise espectral em imagens da região de São Petersburgo (Oeste da Rússia), Krankina et al., (2008) identificaram alto fator de reflectância correlacionado ao substrato herbáceo seco das turfeiras. No Brasil, Borges (2012) utilizou fotografias aéreas e imagens orbitais para efetuar análise espaço-temporal dos avanços da ocupação antrópica em áreas de preservação permanente na bacia do Rio Uberabinha.

Com base na hipótese de que o uso das áreas adjacentes às turfeiras da SdEM tem sido intensificado nos últimos 50 anos, o objetivo deste trabalho foi cartografar cronologicamente (1964 - 2014) áreas adjacentes à turfeiras da SdEM para identificar e quantificar a ocupação por atividades antrópicas nos últimos 50 anos, por meio de técnicas de geoprocessamento. As turfeiras investigadas neste trabalho foram identificadas e mapeadas por Silva et al., (2013b) por técnicas de geoprocessamento.

\section{CARACTERIZAÇÃO DA ÁREA DE ESTUDO}

As turfeiras analisadas neste trabalho estão situadas em três municípios: Diamantina, Datas e Gouveia. (Figura 1). A descrição dos limites elaborados para definir as áreas adjacentes está especificada no item préprocessamento.

A SdEM é uma faixa orogênica que limita o sudeste do Cráton São Francisco (Almeida Abreu et al., 1995). Nesta região ocorrem as rochas do Supergrupo Espinhaço (SE), com abundância de quartzitos em conjunto com filitos, conglomerados, e metavulcânicas (ácidas e básicas) subordinadamente (Augustin e Aranha, 2006). Os Grupos Costa Sena e Guinda são as principais unidades estratigráficas da SdEM e ocorrem na região de Diamantina (Silva e Knauer, 2011). O Grupo Guinda, base do SE, é composto principalmente por quartzitos com presença secundária de metarruditos e filitos. Este grupo é 


\section{TÉCNICAS DE GEOPROCESSAMENTO APLICADAS NA IDENTIFICAÇÃO DE USOS DA TERRA NO ENTORNO DAS TURFEIRAS DA SERRA DO ESPINHAÇO MERIDIONAL}

dividido pelas formações Galho do Miguel e Sopa-Brumadinho (Almeida-Abreu, 1995). Estas formações correspondem a mais de $50 \%$ dos tipos de embasamento (substrato rochoso) das turfeiras mapeadas na SdEM (Silva et al.,2013b).

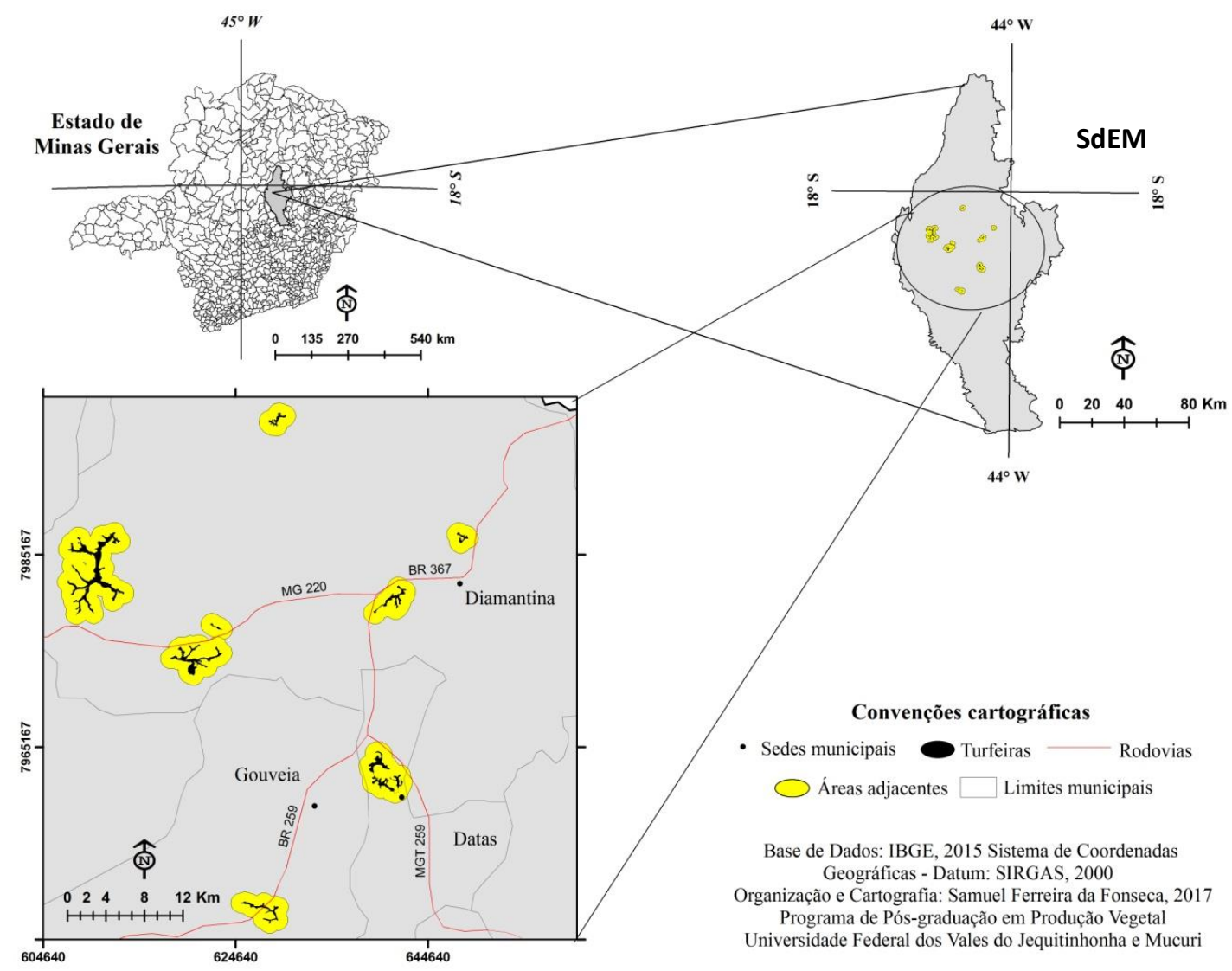

Figura 1 - Mapa de localização dos municípios e turfeiras na Serra do Espinhaço Meridional - SdEM. Embora a SdEM englobe 29 municípios, as turfeiras estudadas neste trabalho estão inseridas em apenas três: Diamantina, Datas e Gouveia.

A SdEM possui características climáticas profundamente influenciadas pela altitude (Campos et al., 2014). Segundo a classificação de Köppen o clima da SdEM é caracterizado como Cwb, ou seja, mesotérmico. A temperatura média anual é de 18,96 oc (Campos et al., 2012) e a precipitação média anual é de é 1.404 mm (Vieira et al., 2010), distribuída principalmente entre os meses de outubro e março (Silva et al., 2005; Silva et al., 2009a).

A área pesquisada pertence ao domínio do Bioma Cerrado, nesta entre altitudes aproximadas de 900 e 1.350 m, a composição da paisagem é dominada por fitofisionomias rupestres (Ribeiro e Walter, 1998; Viana e Lombardi, 2007). Os aspectos geomorfológicos e climáticos na SdEM condicionam a formação de turfeiras de modo que a maioria dos córregos e rios possuem suas cabeceiras localizadas nesses ambientes.

Campos et al., (2017) utilizaram um radar de penetração do solo (GPR) para localizar blocos de quartzito perpendiculares ao padrão de drenagem, que condicionam a formação das turfeiras. Estes autores identificaram quatro tipologias de turfeira: turfeiras confinadas (Complexo Datas, Campus JK, Mendes, Conselheiro Mata), turfeiras subsuperficiais (Batatal), turfeiras estruturais (Pau de Fruta) e turfeiras de vale suspenso. As turfeiras confinadas ocorrem em depressões hidromórficas formadas pela degradação de 


\section{TÉCNICAS DE GEOPROCESSAMENTO APLICADAS NA IDENTIFICAÇÃO DE USOS DA TERRA NO ENTORNO DAS TURFEIRAS DA SERRA DO ESPINHAÇO MERIDIONAL}

rochas mais susceptíveis ao intemperismo, confinadas entre quartzitos. As turfeiras subsuperficiais ocorrem nas planícies quartzíticas e foram soterradas por sedimentos arenosos nos períodos mais secos do Pleistoceno e Holoceno. Nas turfeiras estruturais a rede de drenagem é linear devido a adaptação a falhas, formando ângulos com os limites da foliação do quartzito, o que gera soleiras que mantém o ambiente hidromórfico e favorece a formação destes pedoambientes (Campos et al., 2017).

Os principais solos do entorno das turfeiras são (Minas Gerais, 2010): (i) Cambissolo Háplico tb Distrófico típico (CXbd), (ii) Latossolo Vermelho Amarelo Distrófico típico (LVAd), (iii) Neossolo Litólico Distrófico típico (RLd), e (iv) Neossolo Quartzarênico órtico típico (RQo). Nas turfeiras predominam os organossolos representados pelos Organossolo Háplico Fíbrico típico, Organossolo Háplico Hêmico típico e Organossolo Háplico Sáprico típico (Embrapa, 2013). Estes solos são constituídos por material orgânico, que apresentam horizonte hístico. Além disso, são solos saturados com água durante a maior parte do ano, na maioria dos anos, a menos que artificialmente drenados.

\section{PROCEDIMENTO METODOLÓGICO}

Para a realização da análise espacial e temporal nas turfeiras selecionadas foram utilizadas fotografias aéreas (USAF- de 1964 e Espinhaço, de 1979) e imagens orbitais do satélite Landsat 5 (de 1984, de 1995 e de 2005) e Landsat 8 (de 2014). As imagens orbitais foram adquiridas junto a United States Geological Survey (USGS). Essas imagens foram georreferenciadas na base cartográfica por meio de reprojeção.

A base cartográfica usada corresponde às cartas topográficas editadas pela Divisão de Serviço Geográfico - DSG, do Instituto Brasileiro de Geografia e Estatística - IBGE, de 1977 (escala $1 / 100.000$ ). Todas as imagens e fotografias aéreas foram georreferenciadas utilizando os pontos de controle adquiridos em campo. Primeiro, foram inseridas fotografias na maior escala (1/25.000), que serviram de base para todas as demais, as quais foram sobrepostas com objetivo de realização da análise multi-escalar e multi-temporal.

O local, a área (ha) e altitude média das turfeiras analisadas estão na tabela 1 . Os critérios utilizados para escolha destas turfeiras foram: facilidade de acesso e maior volume de informações disponíveis. Foram analisados $16.468,38$ ha de áreas adjacentes a 8 turfeiras. 0 recorte temporal foi o período entre 1964 e 2014 (50 anos). Mais detalhes sobre a área pesquisada são encontrados na tabela 2.

Tabela 1 - Turfeiras estudadas, áreas adjacentes e altitude (Adaptado de Silva et al., 2013).

\begin{tabular}{cccc}
\hline Localidade da Turfeira & Área (ha) & Área adjacente (ha) & Altitude (m) \\
\hline Pau de Fruta & 81,75 & $1.601,63$ & 1.366 \\
São João da Chapada & 61,73 & 926,72 & 1.340 \\
Complexo Datas & 266,19 & $2.379,70$ & 1.311 \\
Campus JK & 44,66 & 753,10 & 1.398 \\
Mendes & 307,34 & $2.586,23$ & 1.172 \\
Batatal & 16,9 & 621,90 & 1.165 \\
Gouveia & 122,55 & $1.686,34$ & 1.070 \\
Conselheiro Mata & 847,69 & $5.912,77$ & 990 \\
\hline Total & $\mathbf{1 . 7 4 8 , 8 1}$ & $\mathbf{1 6 . 4 6 8 , 3 8}$ & \\
\hline
\end{tabular}




\section{TÉCNICAS DE GEOPROCESSAMENTO APLICADAS NA IDENTIFICAÇÃO DE USOS DA TERRA NO ENTORNO DAS TURFEIRAS DA SERRA DO ESPINHAÇO MERIDIONAL}

Para Silva e Silva (2017) a ocorrência das turfeiras em as altitudes variadas está correlacionada com a idade destes pedoambientes. Paras estes autores, em altitudes entre 1.000 e 1.200 e acima de 1.700 m ocorrem turfeiras holocênicas, aquelas situadas entre 1.200 e 1.700 m, são datadas do Pleistoceno Superior.

Tabela 2 - Outras características das turfeiras estudadas.

\begin{tabular}{|c|c|c|c|}
\hline Turfeira & Sigla & Localização & Função socioambiental \\
\hline Pau de Fruta & $\mathrm{PF}$ & $\begin{array}{c}\text { Margem esquerda da rodovia BR } \\
367 \text { (Diamantina/Gouveia) }\end{array}$ & $\begin{array}{c}\text { Nascente do Córrego das Pedras. } \\
\text { Abastece Diamantina }\end{array}$ \\
\hline $\begin{array}{l}\text { São João da } \\
\text { Chapada }\end{array}$ & SJ & $\begin{array}{c}\text { Próximo a comunidade } \\
\text { homônima, } 43 \mathrm{~km} \text { a NE do núcleo } \\
\text { urbano de Diamantina }\end{array}$ & Coleta de sempre vivas e pastagens \\
\hline Complexo Datas & $C D$ & $\begin{array}{c}\text { Município de Datas, } \\
\text { entroncamento das Rodovias BR } \\
259 \text { com BR } 367\end{array}$ & $\begin{array}{c}\text { Nascente do Ribeirão Datas, } \\
\text { Abastece o município homônimo }\end{array}$ \\
\hline Campus JK & JK & $\begin{array}{l}\text { Em frente ao campi da UFVJM no } \\
\text { Parque Estadual do Biri-Biri }\end{array}$ & $\begin{array}{l}\text { Nascente do Córrego da Roda. } \\
\text { Pastagens. }\end{array}$ \\
\hline Mendes & ME & $\begin{array}{l}\text { Rodovia Estadual MG 220, a W da } \\
\text { área urbana de Diamantina. }\end{array}$ & $\begin{array}{l}\text { Nascente do Ribeirão das Varas. } \\
\text { Abastecimento da comunidade } \\
\text { Mendes. }\end{array}$ \\
\hline Gouveia & GV & $\begin{array}{l}\text { Rodovia Federal BR } 259 \text { a SW da } \\
\text { cidade de Diamantina }\end{array}$ & $\begin{array}{c}\text { Nascente do Córrego Água Limpa. } \\
\text { Pastagens }\end{array}$ \\
\hline Conselheiro Mata & $\mathrm{CM}$ & $\begin{array}{c}\text { Rodovia Estadual MG 220, a W da } \\
\text { área urbana de Diamantina. }\end{array}$ & $\begin{array}{c}\text { Nascente do Córrego da Fazenda, } \\
\text { abastece sitiantes locais }\end{array}$ \\
\hline
\end{tabular}

Observações: Informações adquiridas em campanhas de campo e nos autores. (Chula et al., 1995; Campos et al., 2014; Silva e Silva, 2017)

\section{APLICAÇÃO DE TÉCNICAS DE GEOPORCESSAMENTO}

O processamento de dados foi realizado em várias etapas: (i) pré-processamento (I e II), (ii) processamento, e (iii) pós-processamento (Figura 2).

\section{PRÉ-PROCESSAMENTO I (FOTOGRAFIAS AÉREAS)}

Neste trabalho adotou-se um Buffer com raio de $1.000 \mathrm{~m}$ a partir dos limites de cada turfeira, pois corresponde a uma faixa capaz de influenciá-las negativamente caso sejam identificadas atividades antrópicas. Essa distância foi delimitada em decorrência dos aspectos geomorfológicos e hidrológicos das próprias turfeiras, pois são áreas rebaixadas em relação ao entorno, relativamente planas e propícias a acumular sedimentos (SILVA et al., 2009ab; CAMPOS et al., 2014).

As chaves de interpretação referentes aos usos da terra no entorno das turfeiras foram validadas por meio dos trabalhos de campo, que possibilitaram maior entendimento a respeito das feições geográficas de cada imagem. Uma vez que as chaves de interpretações são específicas para cada situação (Rosa, 2009), foram elaboradas chaves distintas para cada conjunto de dados analisados (fotografias aéreas de 1964 e 79). 


\section{TÉCNICAS DE GEOPROCESSAMENTO APLICADAS NA IDENTIFICAÇÃO DE USOS DA TERRA NO ENTORNO DAS TURFEIRAS DA SERRA DO ESPINHAÇO MERIDIONAL}

\section{Fluxograma 1}

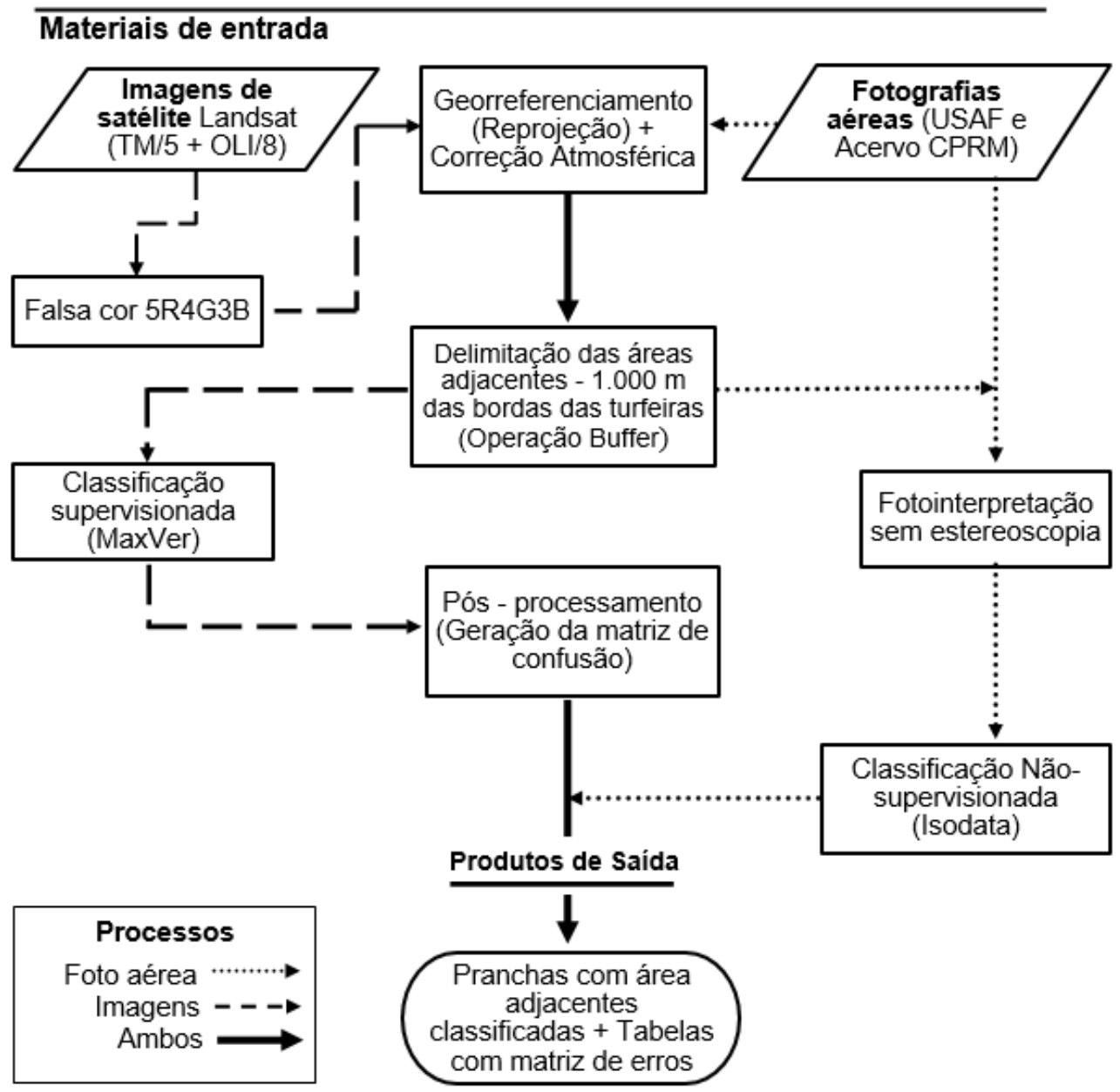

Figura 2 - Procedimentos operacionais realizados na identificação de usos da terra nas áreas adjacentes às turfeiras. As imagens de satélites foram submetidas a classificação supervisionada (Maxver) e as fotografias aéreas a Fotointerpretação sem estereoscopia e classificação não supervisionada (Isodata). A Matriz de confusão foi gerada somente a partir da classificação das imagens de satélites.

PRÉ - PROCESSAMENTO II - (IMAGENS DE SATÉLITES)

Quanto à correção atmosférica, estas imagens são distribuídas já corrigidas (Figura 2). São denominadas imagens de Reflectância de Superfície e estão corrigidas pelo método $6 \mathrm{~S}$ (Second Simulation of a Satellite Signal in the Solar Spectrum) proposto por Vermoteet al., (1997). O método 6S é um modelo de transferência radiativa, cuja principal vantagem consiste no fato de considerar o processo de absorção da radiação eletromagnética (Masek et al., 2006; Ponzoni et al., 2012; Almeida et al., 2015; Fonseca et al., 2014; 2016).

\section{PROCESSAMENTO}

\section{FOTOINTERPRETAÇÃO E CLASSIFICAÇÃO}

Após a elaboração das chaves de interpretação, as fotografias aéreas selecionadas foram submetidas à fotointerpretação sem estereoscopia, seguindo método proposto por Moreira et al., (2004). A imagens de satélites dos anos de 1984, 1995, 2005 e 2014 foram submetidas à classificação supervisionada (Figura 


\section{TÉCNICAS DE GEOPROCESSAMENTO APLICADAS NA IDENTIFICAÇÃO DE USOS DA TERRA NO ENTORNO DAS TURFEIRAS DA SERRA DO ESPINHAÇO MERIDIONAL}

2) utilizando o algoritmo MaxVer (Máxima verossimilhança) por meio do aplicativo $\mathrm{ENVI}^{\mathrm{TM}}$ 4.5. (Meneses e Sano, 2012). Para os dados referentes aos anos de 1964 e 1979 foram realizadas fotointerpretações sem o uso de estereoscópio e aplicado o classificador Isodata, com 4 classes, 15 interações, valor mínimo de 50 pixels (por classe) e probabilidade erro de $5 \%$.

\section{PÓS-PROCESSAMENTO}

\section{MATRIZ DE CONFUSÃO E CONFIABILIDADE DA} CLASSIFICAÇÃO

A matriz de confusão (Figura 2) foi elaborada a partir do ENVI $4.5^{\mathrm{TM}}$. Os layouts foram criados por meio do aplicativo ArcGIS ${ }^{\text {TM }}$ 9.3. As rotinas realizadas por meio do pósprocessamento possibilitaram interpretação e análise da precisão dos resultados, bem como a correção dos mesmos (Silva, 2003; Fonseca et al., 2014). A confiabilidade da classificação pode ser analisada por meio do Índice Kappa (k) que acentua a probabilidade de acertos da classificação (Silva, 2003; Rosa, 2009).

Em trabalhos de campo foram adquiridos pontos de controle com receptor GNSS (sinal GPS). Este receptor foi calibrado para o datum WGS 84 (World Geodetic System 1984) e apresentou precisão média de $2 \mathrm{~m}$.

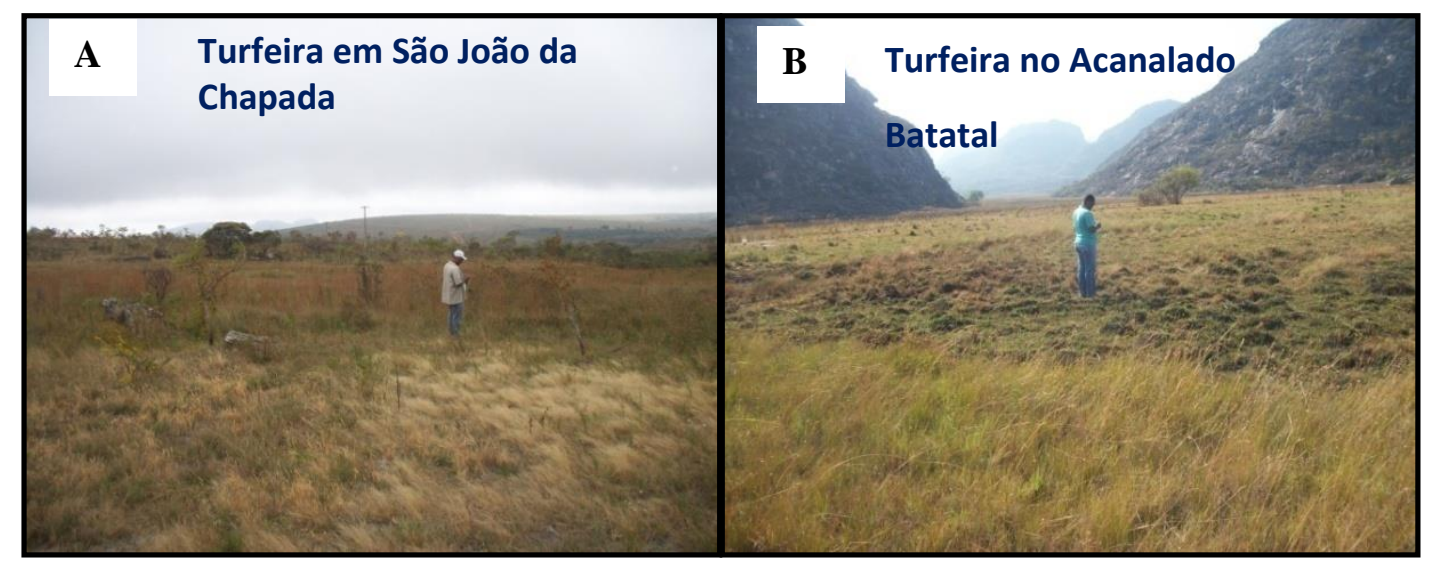

Figura 3 - Aquisição de verdade de campo (São João da Chapada e Acanalado Batatal). Em ambas as turfeiras se observa a presença da fitofisionomia Campo Limpo Úmido. Campanhas de campo realizadas em: 14/09/2015 (São João da Chapada) e dia 19/10/2015 (Acanalado Batatal).

\section{RESULTADOS}

Na turfeira Pau de Fruta e área adjacente não ocorreram intervenções antrópicas entre 1964 e 1984. Todavia, a partir de 1995, foram inseridos na área de estudo 10,80 ha de eucalipto, que representa $0,64 \%$ de sua área adjacente (Tabela 3 e Figura 5). Apesar de se situar em uma área de proteção, a proximidade com o núcleo urbano de Diamantina $(5 \mathrm{~km})$ a torna vulnerável a intervenções antrópicas e incêndios são recorrentes. Além disso, nesta área foi identificado plantio de eucalipto.

Não foram identificadas intervenções antrópicas nas adjacências da turfeira SJ entre 1964 e 1984. Em 1995 foram identificados 39,38 ha de pastagens, cuja área foi ampliada para
45,85 ha em 2005 e 49,80 ha em 2014 (Tabela 3 e Figura 5); respectivamente 4,25, 4,95 e 5,27 \% da área adjacente a esta turfeira. O avanço das pastagens amplia o risco de degradação da turfeira, devido à sua compactação pelo pisoteio e por deposição de sedimentos provenientes da erosão.

Nas turfeiras do Complexo Datas (CD) entre 1964 a 1984 foi identificada em suas adjacências apenas a área urbana do município homônimo, ampliada de 22,98 ha em 1964 para 53,08 ha em 1984 e cujo abastecimento de água advém das turfeiras. A partir de 1995 foram identificados 45,59 ha de eucalipto e 56,96 ha com outras culturas (morango e milho), cujas áreas foram ampliadas para respectivamente 


\section{TÉCNICAS DE GEOPROCESSAMENTO APLICADAS NA IDENTIFICAÇÃO DE USOS DA TERRA NO ENTORNO DAS TURFEIRAS DA SERRA DO ESPINHAÇO MERIDIONAL}

para 146,16 ha e 292,58 ha em 2014 (Tabela 3 e Figura 5), perfazendo $18,43 \%$ de área adjacente. O cultivo do milho e do morango amplia enormemente o risco de degradação desse ecossistema, pela sedimentação e pela contaminação com resíduos de agroquímicos, notadamente do cultivo de morango, inserido neste município a partir de 2005 (Guimarães et al., 2015).

Tabela 3 - Usos da terra nas áreas adjacentes às turfeiras, entre 1964 e $2014 .$.

\begin{tabular}{|c|c|c|c|c|c|c|c|c|c|c|c|c|}
\hline \multirow{2}{*}{ Turfeira } & \multicolumn{2}{|l|}{1964} & \multicolumn{2}{|l|}{1979} & \multicolumn{2}{|l|}{1984} & \multicolumn{2}{|l|}{1995} & \multicolumn{2}{|l|}{2005} & \multicolumn{2}{|l|}{2014} \\
\hline & (ha) & (\%) & (ha) & $(\%)$ & (ha) & (\%) & (ha) & (\%) & (ha) & (\%) & (ha) & (\%) \\
\hline & \multicolumn{12}{|c|}{ Eucaliptocultura } \\
\hline $\begin{array}{l}\text { Pau de } \\
\text { Fruta }\end{array}$ & --- & --- & --- & --- & --- & --- & 10,80 & 0,64 & 10,80 & 0,64 & 10,80 & 0,64 \\
\hline $\begin{array}{l}\text { Complexo } \\
\text { Datas }\end{array}$ & --- & --- & --- & --- & --- & --- & 45,59 & 1,92 & 45,40 & 1,91 & 146,2 & 6,14 \\
\hline $\begin{array}{l}\text { Conselheiro } \\
\text { Mata }\end{array}$ & --- & --- & --- & --- & --- & --- & --- & --- & 32,40 & 0,55 & 158,9 & 2,69 \\
\hline \multirow[t]{2}{*}{ Mendes } & --- & --- & -- & -- & --- & --- & -- & -- & 6,80 & 0,26 & 22,53 & 0,87 \\
\hline & \multicolumn{12}{|c|}{ Outras culturas } \\
\hline $\begin{array}{l}\text { Complexo } \\
\text { Datas }\end{array}$ & --- & --- & --- & --- & --- & --- & 56,96 & 2,39 & 47,50 & 2,00 & 292,58 & 12,29 \\
\hline \multirow[t]{2}{*}{ Mendes } & --- & --- & -- & -- & -- & --- & 11,6 & 0,45 & 21,66 & 0,84 & 19,88 & 0,77 \\
\hline & \multicolumn{12}{|c|}{ Pastagens } \\
\hline $\begin{array}{l}\text { São João da } \\
\text { Chapada }\end{array}$ & --- & --- & --- & --- & --- & --- & 39,38 & 4,25 & 45,85 & 4,95 & 49,80 & 5,27 \\
\hline Campus JK & --- & --- & --- & --- & 13,00 & 1,73 & 33,36 & 4,43 & 36,83 & 4,89 & 33,90 & 4,50 \\
\hline Gouveia & 378,60 & 22,45 & 378,60 & 22,45 & 350,20 & 20,77 & 421,30 & 24,98 & 466,30 & 27,65 & 438,90 & 26,03 \\
\hline
\end{tabular}

As pastagens no entorno da turfeira Campus JK (JK) foram implantadas a partir de 1984, quando ocupavam 13 ha. Em 1995 ocupavam 33,36 ha, valor que permaneceu aproximadamente constante até 2014 e que corresponde a 4,50\% da área adjacente (Tabela 3 e Figura 5), uma vez que em 1999 foi criado o Parque Estadual do Biribiri, unidade de conservação de proteção integral. Na turfeira Mendes (ME) a cafeicultura foi implantada na área adjacente a partir de 1995, quando ocupava 11,6 ha, foi ampliada em 2005 para 21,66 ha e em 2014 ocupava 19,88 ha. O cultivo do eucalipto foi identificado a partir de 2005, quando ocupava 6,8 ha, ampliado para 22,53 ha em 2014 (Tabela 3 e Figura 6). Atualmente, apenas 1,64 \% de sua área adjacente é utilizada por atividades agrícolas intensivas.

Áreas adjacentes a turfeira Gouveia (GV) estavam cultivadas com pastagens desde 1964. Entre 1964 e 1984 a área de pastagens diminuiu de 378,57 para 350,24 ha. Em 1995 foi ampliada para 421,25 ha e novamente ampliada para 466,34 ha em 2005. Em 2014 foram identificados 438,87 ha de pastagens, o que corresponde a 26,03\% de sua área adjacente. Até 1995 não foram identificados usos intensivos da terra nas adjacências da turfeira Conselheiro Mata (CM). Em 2005 foram identificados 32,40 ha cultivados com eucalipto, ampliado para 158,88 ha em 


\section{TÉCNICAS DE GEOPROCESSAMENTO APLICADAS NA IDENTIFICAÇÃO DE USOS DA TERRA NO ENTORNO DAS TURFEIRAS DA SERRA DO ESPINHAÇO MERIDIONAL}

2014, o que corresponde a 2,69\% da área adjacente (Tabela 3 e Figura 6).

A turfeira Batatal (BT) é um caso peculiar, nesta não foi identificado nenhum uso intensivo da terra durante o período analisado. Entretanto, durante os trabalhos de campo foram observadas queimadas na mesma. De acordo com o histórico regional as queimadas são uma prática agrícola de subsistência, utilizada para queimar a vegetação de campo e, desta maneira, forçar seu brotamento e favorecer o pastoreio (Figura 4).

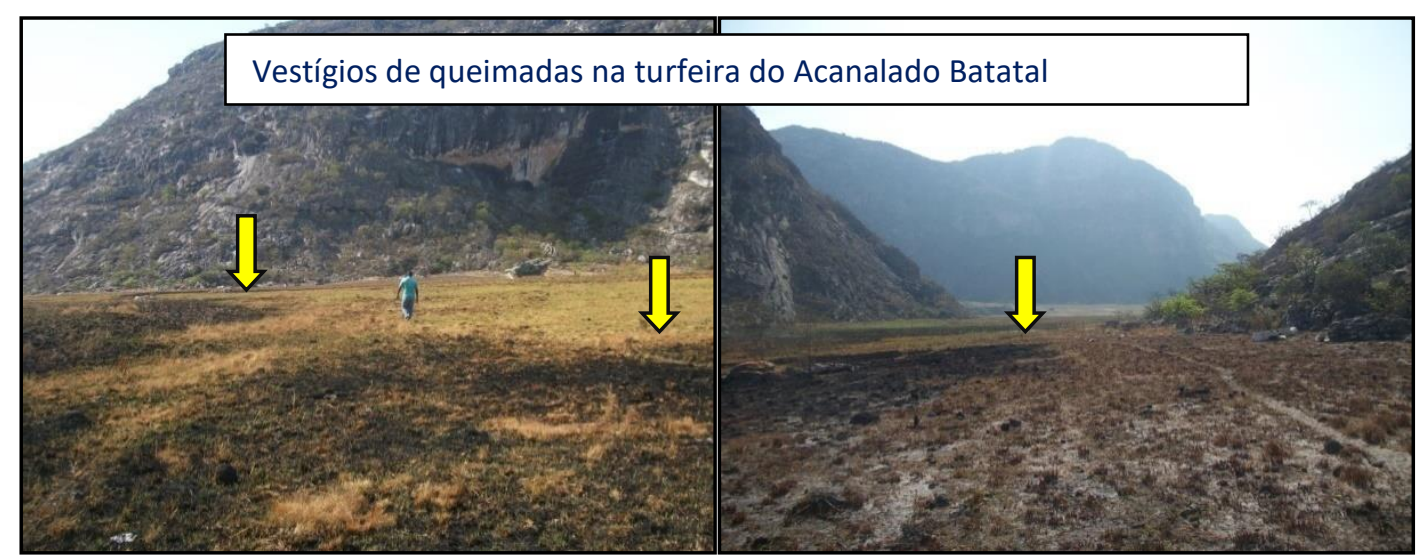

Figura 4 - Sinais de queimadas na área da turfeira do Acanalado Batatal. Fotografias adquiridas em 19/10/2015. Depressão Interplanáltica em Batatal, cujo embasamento pertence à Formação Galho do Miguel. Não foi observado nenhum tipo de uso sistemático da terra na mesma, portanto não foram realizados os procedimentos da classificação na área adjacente as esta turfeira.

As queimadas também favorecem a germinação das sementes e o florescimento das sempre-vivas (Sygonanthus sp, Paepaluntus sp, dentre outras), cujo extrativismo é uma importante atividade econômica regional (Silva et al., 2005). 


\section{TÉCNICAS DE GEOPROCESSAMENTO APLICADAS NA IDENTIFICAÇÃO DE USOS DA TERRA NO ENTORNO DAS TURFEIRAS DA SERRA DO ESPINHAÇO MERIDIONAL}

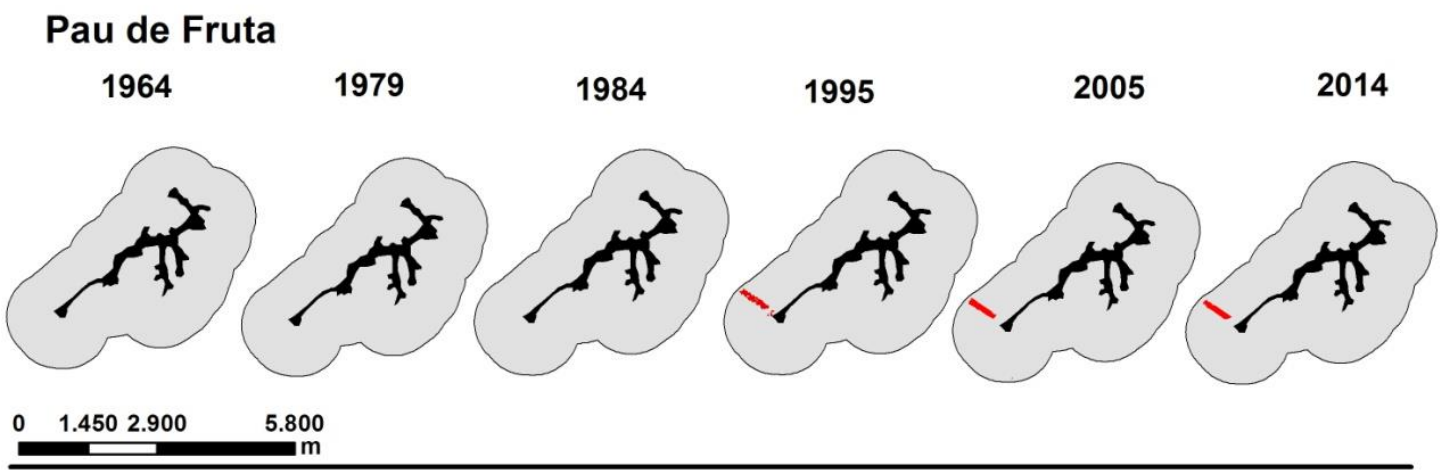

São João da Chapada


$0 \quad 1.250 \quad 2.500$

5.000

\section{Complexo Datas}


Figura 5 - Usos da terra nas áreas adjacentes à turfeiras Pau de Fruta, São João da Chapada, Complexo Datas e Campus JK, entre 1964 e 2014. Observa-se o avanço das atividades antrópicas nas áreas adjacentes às turfeiras após 1995. 


\section{TÉCNICAS DE GEOPROCESSAMENTO APLICADAS NA IDENTIFICAÇÃO DE USOS DA TERRA NO ENTORNO DAS TURFEIRAS DA SERRA DO ESPINHAÇO MERIDIONAL}

\section{Mendes}

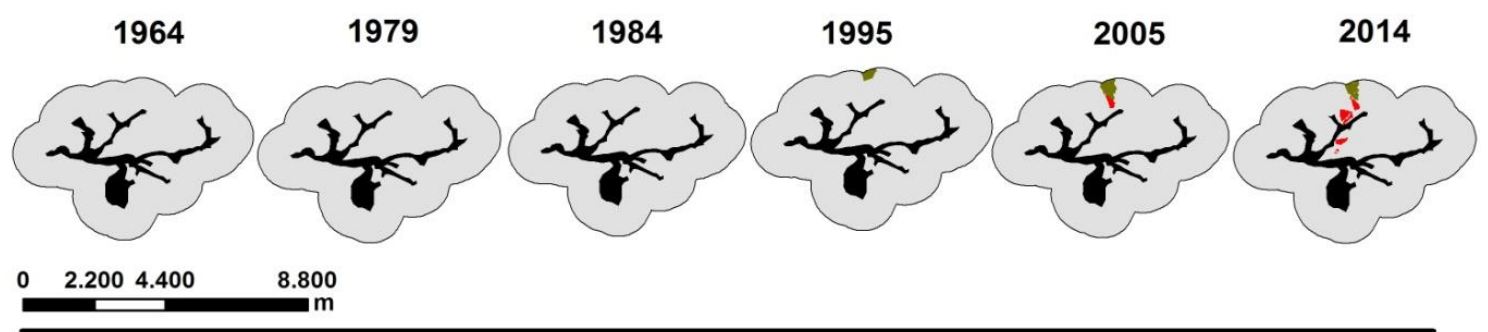

\section{Gouveia}

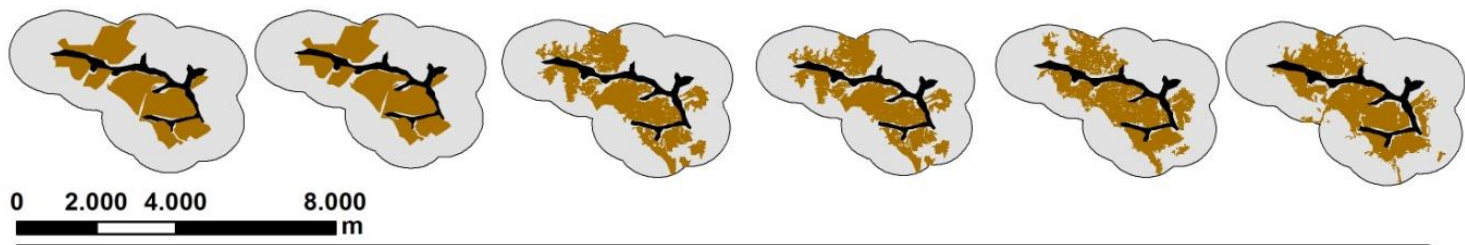

\section{Conselheiro Mata}
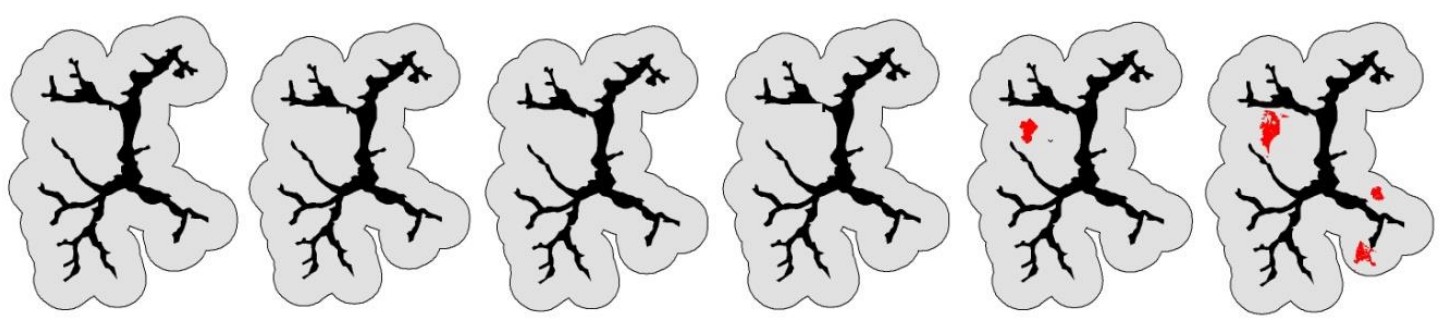

2.5005 .000

10.000



Figura 6 - Usos da terra nas áreas adjacentes das turfeiras Mendes, Gouveia a Conselheiro Mata, entre 1964 e 2014. O principal destaque é a turfeira GV, que em 1964 já possuía área adjacente cultivada com pastagens.

DISCUSSÃO

A ocupação das áreas adjacentes às turfeiras se intensificou amplamente após a década de 1990, quando ocorreram mudanças significativas nas políticas ambientais. Estas mudanças induziram a uma grande redução das atividades garimpeiras nos municípios da SdEM (Silva et al., 2005). Em 1964 foram identificadas pastagens apenas na turfeira GV, região na qual a pecuária é, tradicionalmente, a principal atividade econômica. $\mathrm{O}$ avanço das pastagens nas adjacências das turfeiras foi muito lento, uma vez que, em 50 anos, a área ampliada foi de apenas 144 ha. A eucaliptocultura e outras culturas (café, milho e morango), não identificadas até 1984, passaram a ocupar respectivamente cerca de 340 e 312 ha no entorno das turfeiras em 2014 e o crescimento foi exponencial (Figura 7). 


\section{TÉCNICAS DE GEOPROCESSAMENTO APLICADAS NA IDENTIFICAÇÃO DE USOS DA TERRA NO ENTORNO DAS TURFEIRAS DA SERRA DO ESPINHAÇO MERIDIONAL}

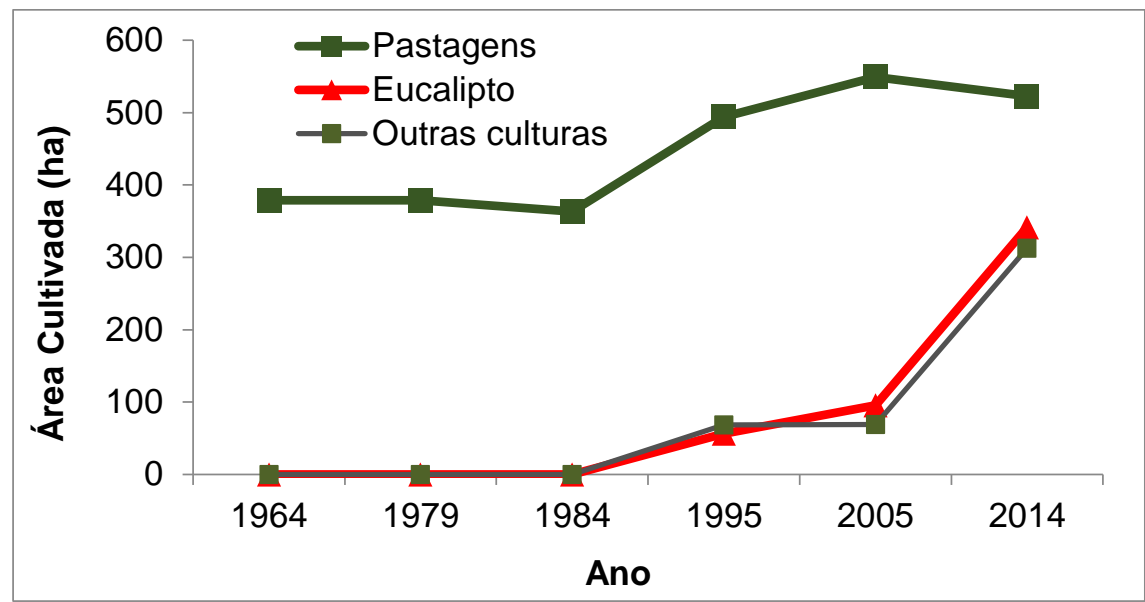

Figura 7 - Usos intensivos da terra nas adjacências das turfeiras. Observa-se o avanço do cultivo de eucalipto e das outras culturas a partir de 1984.

Em 1964 apenas $2,30 \%$ das áreas adjacentes às turfeiras (378 ha) estavam ocupadas com um único uso, pastagens. Este panorama permaneceu estável até 1984. Em 1995 foram identificados 619 ha utilizados intensivamente, dos quais 494 ha eram pastagens, 56 ha era eucaliptocultura e 69 ha estavam cultivados com outras culturas perfazendo 3,76\% das áreas adjacentes. Em 2005 constatou-se crescimento da área ocupada com pastagens e com eucaliptocultura e estabilidade na área cultivada com outras culturas, e o uso da terra passou para 4,33\% das áreas adjacentes. Em 2014 a área de pastagens foi reduzida, mas a eucaliptocultura e as outras culturas avançaram rapidamente e o uso da terra saltou para $7,14 \%$ das áreas adjacentes (Tabela 4). Em 20 anos utilização intensiva das áreas adjacentes às turfeiras cresceu mais de $320 \%$.
O mapeamento cronológico do uso da terra das áreas adjacentes às turfeiras mostrou um significativo avanço de áreas agrícolas. Como as turfeiras da SdEM formam as cabeceiras de importantes bacias hidrográficas do sudeste do Brasil (Silva et al., 2013a), a continuidade da monitoramento do uso das terras no entorno destes ecossistemas pode auxiliar na manutenção do regime hidrológico regional. Por outro lado, a negligência em relação à conservação destes ecossistemas pode comprometer a vazão e a qualidade da água do Rio Jequitinhonha e de importantes afluentes dos rios São Francisco e Doce, afetando as populações que dependem direta ou indiretamente da água destes mananciais. 
FONSECA,S.F., SILVA,A.C., SENNA,J.A.

\section{TÉCNICAS DE GEOPROCESSAMENTO APLICADAS NA IDENTIFICAÇÃO DE USOS DA TERRA NO ENTORNO DAS TURFEIRAS DA SERRA DO ESPINHAÇO MERIDIONAL}

Tabela 4 - Avanço temporal do uso da terra nas áreas adjacentes às turfeiras.

\begin{tabular}{|c|c|c|c|c|c|c|c|c|}
\hline \multirow{3}{*}{ Ano } & \multicolumn{8}{|c|}{ Uso da área Adjacente } \\
\hline & \multicolumn{2}{|c|}{ Pastagem } & \multicolumn{2}{|c|}{ Eucalipto } & \multicolumn{2}{|c|}{ Outras culturas } & \multicolumn{2}{|l|}{ Total } \\
\hline & ha & $\%$ & ha & $\%$ & ha & $\%$ & ha & $\%$ \\
\hline 1964 & 378,57 & 2,30 & --- & $\begin{array}{ll}-- \\
\end{array}$ & $\begin{array}{ll}-- \\
\end{array}$ & --- & 378,57 & 2,30 \\
\hline 1979 & 378,57 & 2,30 & --- & --- & --- & --- & 378,57 & 2,30 \\
\hline 1984 & 363,24 & 2,21 & --- & --- & --- & --- & 363,24 & 2,21 \\
\hline 1995 & 493,99 & 3,00 & 56,39 & 0,34 & 68,56 & 0,42 & 618,94 & 3,76 \\
\hline 2005 & 549,02 & 3,33 & 95,40 & 0,58 & 69,16 & 0,42 & 713,52 & 4,33 \\
\hline 2014 & 522,57 & 3,17 & 341,37 & 2,07 & 312,46 & 1,90 & 1176,40 & 7,14 \\
\hline
\end{tabular}

Apesar da baixa aptidão agrícola, os solos localizados no entorno da turfeira GV são cultivados com pastagens desde 1964. Mesmo situada nas proximidades da estrada vicinal MG 220 e do leito da estrada de Ferro Corinto Diamantina, desativada em 1970, não foram identificados usos da terra nas adjacências da turfeira ME entre 1964 e 1984.

\section{CONCLUSÕES}

Cabe ressaltar a importância das turfeiras estudadas enquanto áreas que atuam como reservatórios de água (retém e redistribui água ao longo do ano para os principais mananciais da SdEM). São ecossistemas particulares que possuem ampla funcionalidade, portanto, uma ocupação antrópica, ainda que reduzida em seu entorno pode, com o passar dos anos, prejudicar estas áreas e até mesmo culminar na redução drástica do volume de água de vários municípios, inclusive Diamantina, que capta água oriunda de turfeiras.

A área utilizada com atividades agrícolas (pastagem, eucalipto e outras culturas) nas adjacências das turfeiras estudadas passou de 378,57 ha, em 1964, para 1.176,40 ha, em 2014. A atividade agrícola mais intensificada nas áreas adjacentes às turfeiras foi o cultivo de eucalipto, que não era cultivado em 1964 e em 2014 ocupava 341,37 ha. Outras culturas, que não eram plantadas nas adjacências das turfeiras em 1964, passaram a ocupar 312,46 ha em 2014.
As áreas adjacentes às turfeiras praticamente não eram utilizadas de forma sistemática até a década de 1990. A decadência das atividades de mineração de diamante nos municípios de Diamantina e Datas coincide com a intensificação do uso da terra nas áreas adjacentes às turfeiras.

O avanço da antropização nas áreas adjacentes às turfeiras nas últimas décadas sinaliza a urgência em se criar mecanismos legais de proteção para esses ecossistemas e de estabelecer diretrizes para o planejamento da ocupação de suas áreas adjacentes. Além disso, estudos temáticos, focados nas alterações causadas pelo uso e ocupação destes pedoambientes e entorno devem ser realizados com vistas a identificar consequências nos serviços ambientais prestados por estes ecossistemas. Há outros fatores que são responsáveis pela disponibilidade de água, mas o papel das turfeiras é singular.

\section{NOTA}

Este trabalho é parte da dissertação de mestrado do primeiro autor, defendida em 10.03.2016, no Programa de Pós-graduação em Produção Vegetal pela Universidade Federal dos Vales do Jequitinhonha e Mucuri (UFVJM).

\section{AGRADECIMENTO}

A Coordenação de Aperfeiçoamento de Pessoal de Nível Superior (CAPES) pela bolsa de 


\section{TÉCNICAS DE GEOPROCESSAMENTO APLICADAS NA IDENTIFICAÇÃO DE USOS DA TERRA NO ENTORNO DAS TURFEIRAS DA SERRA DO ESPINHAÇO MERIDIONAL}

mestrado do primeiro autor. Ao programa de Pós-graduação em Produção Vegetal da Universidade Federal dos Vales do Jequitinhonha e Mucuri. Á Fundação de Amparo a Pesquisa do Estado de Minas Gerais (FAPEMIG) pelos recursos dos processos no CAG APQ 01614-14 e CAG PPM 00568-16.

\section{REFERENCIAS}

ALMEIDA-ABREU, P. A. (1995) O Supergrupo Espinhaço da Serra do Espinhaço Meridional (Minas Gerais): o rifte, a bacia e o orógeno. Geonomos, v.3, n.1, p.1-18. 1995.

ALMEIDA, R. V. J.; GONCALVES, M. D. O.; SILVA, A. C.; SENNA, J. A. (2015) Comparação dos Métodos de Correção Atmosférica: 6S e DOS processadas em dados do sensor TM/Landsat 5 e correspondentes a região de ocorrência da turfeira PdF. IN: Anais do XVII Simpósio Brasileiro de Sensoriamento Remoto - SBSR. João Pessoa. São José dos Campos: INPE, p. 6861-6866.

AUgustin, C. H. R. R.; ARANHA, P. R. A. Piping em Área de Voçorocamento, Noroeste de Minas Gerais. Revista Brasileira de Geomorfologia, v. 1, p. 9-18, 2006.

BISPO, D. F. A.; SILVA, A. C.; MATOSINHOS, C. C.; SILVA, M. L. N.; BARBOSA, M. S.; SILVA, B. P. C.; BARRAL, U. M. (2015) Characterization of headwaters peats of the Rio Araçuaí, Minas Gerais State, Brazil. Revista Brasileira de Ciência do Solo, v.39, p.475 - 489. Doi:10.1590/01000683rbcs20140337

BISPO, D. F. A.; SILVA, A. C.; CHRISTOFARO, C.; SILVA, M. L. N.; BARBOSA, M. S.; SILVA, B. P. C.; BARRAL, U. M.; FABRIS, J. D.(2016) Hydrology and carbon dynamics of tropical peatlands from Southeast Brazil. Catena (Cremlingen), 143, p. 18 - 25.Doi:10.1016/j.catena.2016.03.040

BORGES, F. A. (2012) Caracterização temporal das áreas úmidas e de preservação permanente da porção do alto e médio curso da bacia hidrográfica do Rio Uberabinha, MG com aplicação de técnicas de Geoprocessamento. Dissertação, Universidade Federal de Uberlândia - UFU. Departamento de Geografia.

CAMPOS, J. R. R.; SILVA, A. C.; VIDAL-TORRADO, P. (2012) Mapping, organic matter mass and water volume of a peatland in Serra do EspinhaçoMeridional. Revista Brasileira de
Ciência do Solo. Vol.36, n.3, pp. 723-732.Doi: 10.1590/S0100-06832012000300004

CAMPOS, J. R. R.; SILVA, A. C.; SILVA, E. B.; VIDALTORRADO, P. (2014) Extração e quantificação de alumínio trocável em Organossolos. Pesquisa Agropecuária Brasileira [online]. Vol.49, n.3, pp. 207-214. Doi:10.1590/S0100204X2014000300007

CAMPOS, J. R. R.; SILVA, A. C.; SLATER, L. ; NANNI, M. R. ; VIDAL-TORRADO, P. (2016) Stratigraphic control and chronology of peat bog deposition in the Serra do Espinhaço Meridional, Brazil. Catena (Cremlingen), v. 143, p. 167-173. Doi:10.1016/j.catena.2016.04.009

CAMPOS, J. R. R.; SILVA, A. C.; NANNI, M. R.; SANTOS, M.; VIDAL-TORRADO, P. (2017). Influence of the structural framework on peat bog distribution in the tropical highlands of Minas Gerais, Brazil. CATENA (Cremlingen), v. 156, p. 228-236

Embrapa - (Empresa Brasileira de Pesquisa Agropecuária), 2013. Sistema Brasileiro de Classificação de Solos - SIBICs. 3ạ ed. Embrapa Solos, Rio de Janeiro.

FONSECA, S. F.; SANTOS, D. C.; TRINDADE, W. M. (2014) Técnicas de geoprocessamento aplicadas na classificação e avaliação da distribuição das espécies arbóreas nas praças de Buritizeiro/MG. Geografia: Ensino \& Pesquisa, Santa Maria. vol. 18, n. 2, p. 109-122. Doi: $10.5902 / 2236499412503$

FONSECA, S. F.; HERMANO, V. M.; SILVA, A. C. (2016) Mapeamento do uso da terra nos municípios de Janaúba e Nova Porteirinha (MG) usando dados de sensoriamento remoto. Élisée Revista de Geografia da UEG, v. 5, p. 103-119.

GUIMARÃES, A. G.; ANDRADE JUNIOR, V. C. E.; ELSAYED, A. Y. A. M.; FERNANDES, J. S. C.; FERREIRA, M. A. M. (2015) Potencial produtivo de cultivares de morangueiro. Revista Brasileira de Fruticultura, v. 37 , p. 112-120. Doi: 10.1590/0100-2945-400/13

GORE, A. J. P., (1983). Ecosystems of the World. 4B: Mires, Swamp, Bog, Fen and Moor. Regional Studies. Elsevier, Oxford

HORÁK-TERRA, I.; CORTIZAS, A. M.; CAMARGO, P. B.; SILVA, A. C.; VIDAL-TORRADO, P. (2014) Characterization of properties and main processes related to the Genesis and evolution of tropical mountain mires from Serra do Espinhaço 


\section{TÉCNICAS DE GEOPROCESSAMENTO APLICADAS NA IDENTIFICAÇÃO DE USOS DA TERRA NO ENTORNO DAS TURFEIRAS DA SERRA DO ESPINHAÇO MERIDIONAL}

Meridional, Minas Gerais, Brazil. Geoderma, Amsterdam. Vol. 234, 183-197.Doi: 10.1016/j.geoderma.2014.05.008

HORÁK-TERRA, I.; MARTÍNEZ CORTIZAS, A.; DA LUZ, C. F. P.; RIVAS LÓPEZ, P.; SILVA, A. C.; VIDALTORRADO, P. (2015). Holocene climate change in central-eastern Brazil reconstructed using pollen and geochemical records of Pau de Fruta mire (Serra do Espinhaço Meridional, Minas Gerais). Palaeogeography, Palaeoclimatology, Palaeoecology. v.437, p.117-131. Doi:10.1016/j.palaeo.2015.07.027

KRANKINA, O. N.; PFLUGMACHER.D.; FRIEDL, M.; COHEN, W. B.; NEOLSON, P.; BACCINI, A. (2008). Meeting the challenge of mapping peatlands with remotely sensed data. Biogeosciences, vol. 5, 1809-1820.

MASEK, J. G.; VERMOTE, E. F.; SALEOUS, N. E.; WOLFW, R.; HALL, F. G.; HUEMMRICH, K. F.; GAO, F.; KUTLER, J.; LIM, T. K. A Landsat Surface Reflectance Dataset for North America, 19902000. IEEE Geoscience and Remote Sensing Letters, v. 3, n.1, p.68-72, 2006.Doi: 10.1109/LGRS.2005.857030

Mapa de solos do Estado de Minas Gerais: legenda expandida/Universidade Federal de Viçosa; Fundação Centro Tecnológico de Minas Gerais; Universidade Federal de Lavras; Fundação Estadual do Meio Ambiente (2010). Belo Horizonte: Fundação Estadual do Meio Ambiente, 49p.

MOREIRA, M. A.; ADAMI, M.; RUDORFF, B. F. T. (2004) Análise espectral e temporal da cultura do café em imagens Landsat. Pesquisa agropecuária brasileira, Brasília, v.39, n.3, p.223-231. Doi: 10.1590/S0100-204X2004000300004

PONZONI, F. J.; SHIMABUKURO, Y. E.; KUPLICH, T. M. (2012). Sensoriamento Remoto da Vegetação. 2ạ Ed. Revisada e ampliada -- São Paulo: Oficina de textos.

RIBEIRO, J. F.; WALTER, B. M. T. (1998) Fitofisionomias do Bioma do Cerrado. In: Sano, M. S.; Almeida, S. C. (ed.). Cerrado: ambiente e flora. Planaltina: EMBRAPA-CPAC. 556p.

ROSA, R. (2009) Introdução ao Sensoriamento Remoto. 7ạ ed. Uberlândia: EDUFU.

SCHELLEKENS, J.; HORÁK-TERRA, I.; BUURMAN, P.; SILVA, A. C.; VIDAL-TORRADO, P. (2014) Holocene vegetation and fire dynamics in centraleastern Brazil: Molecular records from the Pau de
Frutapeatland. Organic Geochemistry.v.77, p.32 42. Doi:10.1016/j.orggeochem.2014.08.011

SHENG, Y.; SMITH, L. C.; MACDONALD, G. M.; KREMENETSKI, K. V.; FREY, K. E.; VELICHKO, A. A.; LEE, M.; BEILMAN, D. W.; DUBININ, P. (2004) A high resolution GIS-based inventory of the West Siberian peat carbon pool. Global BiogeochemicalCycles, vol. 18, issue3. Doi: 10.1029/2003GB002190

SILVA, A. B. (2003) Sistemas de Informações Georeferenciadas, 236 p. Editora Unicamp. São Paulo/SP.

SILVA, L. L.; KNAUER, L. G. (2011) Posicionamento Estratigráfico da Formação Bandeirinha na Região de Diamantina, Minas Gerais: Grupo Costa Sena ou Supergrupo Espinhaço? Geonomos, v. 19, p. 131-151.Doi: 10.18285/geonomos.v19i2.49

SILVA, A. C.; PEDREIRA, L. S. F.; ALMEIDA-ABREU, P. A. (2005) Serra do Espinhaço Meridional: paisagens e ambientes. 1a. ed. Belo Horizonte: 0 Lutador. Vol. 1. 272p.

SILVA, A. C.; HORÁK, I.; VIDAL-TORRADO, P.; CORTIZAS, A. M.; RECADO, J. M.; CAMPOS, J. R. R. (2009a) Turfeiras da Serra do Espinhaço Meridional - MG: influência da drenagem na composição elementar e substâncias húmicas. Revista Brasileira de Ciência do Solo.33:13991408.Doi:10.1590/S0100-06832009000500031

SILVA, A. C.; HORÁK, I.; CORTIZAS, A. M.; VIDALTORRADO, P.; RECADO, J. M.; GRAZZIOTTI, P. H.; SILVA, E. B.; FERREIRA, C. A. (2009b) Turfeiras da Serra do Espinhaço Meridional - MG: Caracterização e classificação. Revista Brasileira de Ciência do Solo.33:1385-1398.Doi: 10.1590/S0100-06832009000500030

SILVA, E. V.; SILVA, A. C.; PEREIRA, R. C.; CAMARGO, P. B.; SILVA, B. P. C.; BARRAL, U. M.; MENDONCA FILHO, C. V. (2013a) Composição lignocelulósica e isótopica da vegetação e da matéria orgânica do solo de uma turfeira tropical: I - composição florística, fitomassa e acúmulo de carbono. Revista Brasileira de Ciência do Solo, v. 37 p. 121-133. Doi: 10.1590/S010006832013000100013

SILVA, M. L.; SILVA, A. C.; SILVA, B. P. C.; BARRAL, U. M.; SOARES, P. G. S.; VIDAL-TORRADO, P. (2013b) Surface Mapping, organic matter and water stocks in peatlands of the Serra do Espinhaço Meridional - Brazil. Revista Brasileira 


\section{TÉCNICAS DE GEOPROCESSAMENTO APLICADAS NA IDENTIFICAÇÃO DE USOS DA TERRA NO ENTORNO DAS TURFEIRAS DA SERRA DO ESPINHAÇO MERIDIONAL}

de Ciência do Solo. 37:1149-1157. Solar Spectrum, 6S: an overview.IEEE Doi:10.1590/S0100-06832013000500004

SILVA, M. L; SILVA, A. C. (2017). Gênese e evolução de turfeiras nas superfícies geomórficas da Serra do Espinhaço Meridional - MG. Revista Brasileira de Geomorfologia, v. 18, no 1. DOI: http://dx.doi.org/10.20502/www.ugb.org.br rbg.v18i1.1058

SQUEO, F. A.; WARNER, B. G.; ARAVENA, R.; ESPINOZA, D.(2006) Bofedales: high altitude peatlandsofthe central Andes.RevistaChilena de Historia Natural. 79: 245-255.Doi: 10.4067/S0716-078X2006000200010

VERMOTE, E. F.; TANRE, D.; DEUZE, J. L.; HERMAN, M. AND MORCRETTE, J. J. (1997) TransactionsonGeoscienceand Remote Sensing. 35(3): 675- 686.

VIANA, P. L.; LOMBARDI, J. A. (2007) Florística e caracterização dos campos rupestres sobre canga na Serra da Calçada, Minas Gerais, Brasil. Rodriguésia- Revista do Jardim Botânico do Rio de Janeiro. 58 (1): 159-177.

VIEIRA, J. P.G.; SOUZA, M. J. H.; TEIXEIRA, J. M.; CARVALHO, F. P. (2010) Estudo da precipitação mensal durante a estação chuvosa em Diamantina, Minas Gerais. Revista Brasileira de Engenharia Agrícola e Ambiental, Campina Grande - PB. v. 14, n. 7, p.762- 767. Doi: $10.1590 /$ S1415-43662010000700012. 